\title{
Disruptive Innovation vs Disruptive Technology: The Disruptive Potential of the Value Propositions of 3D Printing Technology Startups
}

\author{
Finn Hahn, Søren Jensen, and Stoyan Tanev
}

\author{
"The distinctions we use to build a language and" \\ discuss strategy are as commonsense as left/right \\ and up/down, but they rise from the specifics of the \\ business context rather than everyday life.
}

J.-C. Spender

Engineer, professor, and author

\begin{abstract}
This article describes an empirical study focusing on the classification of existing business opportunities in the 3D printing technology sector. The authors address three research questions. First, how do technology startups integrate new 3D printing technologies into specific market offers? Second, which value propositions are most attractive in terms of interest from the public and investors? Third, how does the degree of disruptiveness of value propositions relate to the degree of interest from the public and investors? The most notable finding is the link between the business traction of 3D printing technology startups and the degree of disruptiveness of their value propositions. Thus, the article provides empirical support for the conceptualization of the degree of disruptiveness of the value proposition as a metric for the evaluation of the business potential of new technology startups.
\end{abstract}

\section{Introduction}

$3 \mathrm{D}$ printing is a term used to describe the production of tangible products by means of digitally controlled machine tools. The novelty of this manufacturing approach consists of the selective addition of materials layer-upon-layer, rather than through machining from solid material objects, moulding, or casting. There is clearly articulated perception by both scholars and practitioners that $3 \mathrm{D}$ printing technologies have the potential to change the traditional manufacturing paradigm as well as to enable the emergence of new innovation practices based on mass customization, user design, and distributed product innovation. As a result, $3 \mathrm{D}$ printing is considered to be a truly disruptive technology. At the same time, however, it is an emerging technology that is exploited today by only a small number of early global adopters (McKinsey \& Company, 2013). It appears to be significantly over-hyped, which could potentially demotivate the variety of potential adopters who could influence the dynamics of its technology adoption life cycle.
The existing literature focusing on 3D printing is very scarce and appears to suffer from a "double disease". First, it appears dominated by consultancy reports and reviews by practitioners, which lack the methodological depth and the predictive power of serious research studies. Such publications contribute to the hype without offering much analytical substance. Second, it is dominated by technical publications, which, although highly valuable, focus on the engineering aspects of the technologies and much less on the specific ways they are expected to disrupt the existing manufacturing and innovation practices. In addition, there seems to be confusion in the use of the terms "disruptive technology" and "disruptive innovation" (Christensen, 2006; Schmidt et al., 2008; Hang et al., 2011), which does not really help in examining the market opportunities associated with specific 3D printing technologies. All this suggests the need for more systematic studies focusing on the potential business and investment opportunities associated with the emergence of 3D printing technologies. 


\section{The Disruptive Potential of the Value Propositions of 3D Printing Technology Startups}

Finn Hahn, Søren Jensen, and Stoyan Tanev

The present article addresses the lack of literature on $3 \mathrm{D}$ printing innovation by offering the results of an empirical study focusing on the classification of emerging business opportunities in the 3D printing technology sector. It starts with a brief description of the technology sector and continues with the description of the methodology. One of the key research steps includes the evaluation of the disruptiveness of the different types of value propositions with respect to existing ways of user involvement in design, manufacturing, and product customization. The evaluation focuses on how the market offers address the needs of new market segments in a convenient and affordable way as well as on the way they address overshot customers in existing markets that are currently overlooked by incumbent firms. The summary of results helps in comparing the degree of disruptiveness of the value propositions to the degree of public and investor interest. The article ends with a brief conclusion which emphasizes some the key findings and helps in conceptualizing the degree of disruptiveness of the value propositions as a metric for the evaluation of the business potential of new technology startups.

\section{The 3D Printing Technology Sector}

The 3D printing sector has enjoyed sustained doubledigit growth in recent years, and it is realistic to forecast the sector to be worth more than $\$ 7.5$ billion USD by 2020 (McKinsey \& Company, 2013). There are clearly opportunities for the adoption of this technology in key sectors such as aerospace, medical devices and implants, power generation, automotive manufacturing, and the creative industries. Many companies have already assessed the technology or have begun using it on a small scale. In addition, 3D printing technologies could reduce the use of materials, energy, and water by eliminating waste together with all additional harmful process enablers, thus having a positive impact on sustainability (Cozmei \& Caloian, 2012). Due to their digital nature, 3D printing technologies are progressively being integrated with the Internet, which enables consumers to engage directly in the design process, and allows for true customer co-creation and personalization. The adoption of $3 \mathrm{D}$ printing is expected to stimulate the emergence of alternative business models and supply-chain management approaches by mitigating the need for expensive tooling, freeing up working capital within the supply chain, and reducing business risk in new product development and innovation. There is a growing perception among both innovation scholars and business experts that 3D printing technologies will generate a new wave of technology adoption that could be associated with the emergence of multiple business opportunities for both technology entrepreneurs and existing firms. There is, however, little research on the specific ways 3D printing technologies are integrated into specific market offers as well as the potential business models that could help in delivering the corresponding value propositions.

Cozmei and Caloian (2012) have summarized the benefits of $3 \mathrm{D}$ printing technologies by pointing out that they are particularly relevant where:

- the production volumes are low, which is typical of companies engaging in small batch production

- the geometries of the parts and their assembly are complex

- the design complexity and capability should be maximized with no cost penalty

- there is a need for shorter lead times

- there is a need to personalize products and there is an opportunity to differentiate by offering unique personalized products

- the fixed-cost tooling cannot easily be amortised into the price of the individual parts

- the customer base is widely distributed and target customers or suppliers have ethical or environmental concerns

- the materials that are used are expensive and difficult to process by conventional means

Despite all the benefits, the adoption of 3D printing technologies is associated with several technological issues, including the lack of a supportive framework, comprehensive underfunding, and the absence of proper industry standards (Royal Academy of Engineering, 2013). A recent roundtable forum hosted by the Royal Academy of Engineering in the United Kingdom enumerated several key problems:

1. Materials: There is a great demand for better materials to be used in 3D printing processes. Although new metal alloys are already addressing some key manufacturing needs, polymers require greater research and development. In addition, whereas metals are often recyclable, polymers have a much lower degree of recyclability. 


\section{The Disruptive Potential of the Value Propositions of 3D Printing Technology Startups}

Finn Hahn, Søren Jensen, and Stoyan Tanev

2. Software: Existing computer-aided design (CAD) systems are not at all suited for exploring the design freedom of $3 \mathrm{D}$ printing processes. The organic shapes required for biomimetics, for example, cannot easily be replicated using existing CAD systems, which are better suited to designs with many straight lines or circles. More importantly, CAD interfaces do not tend to be user friendly. Thus, the software problem is major issue for the adoption of $3 \mathrm{D}$ printing technologies, because the true potential of the new manufacturing paradigm can be actualized only if it reaches the non-expert designer.

3. Data management: Issues associated with data management are related to the need for substantial memory storage capacity, and not the manufacturing technology itself. In this sense, "rather than advancements in the machines themselves, software developments are what will "drive the industry forward" (Royal Academy of Engineering, 2013). It might be worth looking for insights from the development of the electronic design automation (EDA) industry, which could be quite useful in predicting some of the future trends in the evolution of 3D printing software design tools (MacMillen et al., 2000).

4. Sustainability: Although low-volume production offers opportunities for customization and reduction of materials, its benefits for sustainability are not always obvious. Although manufacturers are driven by efficiency goals that lower their carbon emission rates and energy consumption, homemakers can hardly be expected to care that much about wasted materials and energy. In this sense, the democratization of 3D printing design and innovation may introduce uncontrollable sustainability issues.

5. Affordability: There are significant financial overheads for running machines and buying feedstock for the 3D printing manufacturing process. Materials for 3D printing are significantly more expensive than traditional injection moulding materials.

6. Production speed: Although low-volume production using 3D printing technologies is faster than conventional manufacturing, higher-volume production is considerably slower. British experts believe that there will be a need for a new generation of machines in order for $3 \mathrm{D}$ printing to be able to compete and eventually replace injection moulding and casting machines (Royal Academy of Engineering, 2013).
7. Reliability and reproducibility: It is difficult for $3 \mathrm{D}$ printing technologies to compete with traditional techniques in terms of reliability and reproducibility. Traditional manufacturing methods aim for a rejection rate of just a few parts per million, which cannot be achieved with current 3D printing technology (Royal Academy of Engineering, 2013).

8. Intellectual property rights: Compared to traditional manufacturing, there is a much greater potential for users to infringe copyrights using $3 \mathrm{D}$ printing technologies, especially in combination with 3D scanning technology. Insights into this key issue may be gleaned from the experiences and business practices within the open source software domain, which contributed to the rethinking of earlier ways of managing intellectual property rights (Cohendet \& Pénin, 2011).

9. Industry standards: There is a need for a set of standards that would provide the necessary assurance to businesses and manufacturers that 3D printing processes, materials, and technologies are safe and reliable. The challenge here would be to quickly introduce key formal standards to the sector, while leaving room for open innovation.

10. Funding: Government programs to encourage companies to enter the sector and university research focusing on increasing the awareness of potential benefits and business opportunities associated with the adoption of 3D printing technologies could help drive the adoption of the new technology.

\section{Research Methodology}

The objective of this research is to empirically examine emerging 3D printing business opportunities by studying technology startups in this sector. To meet this objective, we have addressed three research questions:

1. How do technology startups integrate new 3D printing technologies into specific market offers?

2. Which value propositions are most attractive in terms of interest from the public and investors?

3. How does the degree of disruptiveness of value propositions relate to the degree of interest from the public and investors? 


\section{The Disruptive Potential of the Value Propositions of 3D Printing Technology Startups}

Finn Hahn, Søren Jensen, and Stoyan Tanev

For the sake of this research, we conceptualize a value proposition by means of three components: i) the specific market offer; ii) the target customer; and iii) the job that the target customer is trying to do by using the market offer (Johnson et al., 2008).

Information about the value propositions was complemented by the specific profit formula and the key human and technology resources used by the startups to develop their market offers. The focus on technology startups (i.e., technology companies incorporated within 3 years from the start of the study) allows the development of insights about emerging business opportunities that are currently explored by entrepreneurs across the world. Finally, the research aims to conceptualize the degree of disruptiveness as part of the evaluation criteria of emerging business opportunities by both entrepreneurs and investors.

\section{Research design}

The research study adopts a combination of qualitative and quantitative approaches. It is based on a research sample of 79 3D printing startups (up to three years old) that were labelled as such on the AngelList startup platform (https://angel.co/3d-printing). The AngelList platform was chosen as a source for data collection because it provides publicly available online information about:

1. The classification of the startups in terms of their main technology orientation.

2. The composition of their executive management team.

3. The websites of the firms with all the additional information about their mission, products, hiring priorities (job announcements), etc.

4. Their investors, and the type and amount of the investments.

5. The number of people interested in following their progress (i.e., their online "followers").

6. The ranking of the firms on the basis of a proprietary composite metric corresponding to their business traction (signal).

We examined the information about each of the 79 startups included in the sample by focusing on: the description of the firm, including its location, year of incorporation, mission statement, etc.; the market of- fer; the target customer; whether the startup offers a product or a service; the number of investors and the total amount of investments attracted by the firm; the public interest in the firm expressed as the number of followers on the AngelList platform; the signal value as a measure of the business traction of the firm, as estimated by the AngelList experts. The market offer of each of the value propositions was analyzed along several constitutive dimensions by examining: whether the offer is hardware or software; whether it integrates the 3D printing technology (and how); whether there are any online tools available to support its use; and whether there are any open source hardware or software products that could complement its value in use. The examination of the market offer, the target customers, and the "job to be done" by the target customers resulted in a classification of the value propositions of all the firms included in the sample and a comparative analysis of the different types of value propositions in terms of their business traction (signal), investments, number of followers and degree of disruptiveness.

In addition to analyzing the startups using the metrics from the AngelList platform, we evaluated the disruptiveness of the value propositions by using the Disrupto-Meter tool suggested by Anthony and colleagues (2008). The tool was designed to evaluate the degree of disruptiveness of company offers to particular customer target segments with respect to existing solutions (including the lack of solutions associated with non-consumption). We used the tool to evaluate the seven value propositions by considering their specific market offers against nine different criteria (Table 1). Each of the nine criteria is evaluated by choosing between one of three options corresponding to 0,5 , or 10 points. At the end, all points are summed to provide the value of the Disrupt-O-Meter up to a maximum of 90 points: the higher the value, the more disruptive the value proposition.

\section{Classification of the Value Propositions}

This section provides an overview of the results from the analysis of the data collected from the AngelList startup platform. The value propositions of the 79 startups were categorized in seven types with respect to their specific market offers (Table 2).

\section{Type A: Access to online printing networks offered by}

firms that do not own the printers

The customer value of the access to such networks is two-fold. First, it offers a relatively easy and affordable option for people or organizations interested in print- 


\section{The Disruptive Potential of the Value Propositions of 3D Printing Technology Startups}

Finn Hahn, Søren Jensen, and Stoyan Tanev

Table 1. Evaluation criteria included in the Disrupt-O-Meter (Anthony et al., 2008)

\begin{tabular}{|c|c|c|c|c|}
\hline & Evaluation Criteria & 0 points & 5 points & 10 points \\
\hline 1 & First-year target & Mass market & Large market segment & Niche market \\
\hline 2 & Customers' opinion about the job to be done & $\begin{array}{l}\text { Needs to be done } \\
\text { better }\end{array}$ & $\begin{array}{l}\text { Needs to be done less } \\
\text { expensively }\end{array}$ & $\begin{array}{l}\text { Needs to be more } \\
\text { easily }\end{array}$ \\
\hline $\mathbf{3}$ & Customers' view on offer & Perfect & Good & Good enough \\
\hline 4 & Customers' view on price & High & Medium & Low \\
\hline 5 & Business model & $\begin{array}{l}\text { What has been always } \\
\text { done }\end{array}$ & $\begin{array}{l}\text { What has been always } \\
\text { done but with a few } \\
\text { tweaks }\end{array}$ & Radically different \\
\hline 6 & Channel to market & Existing & At least $50 \%$ new & Entirely new channel \\
\hline 7 & Competitors' urgency to do something & $\begin{array}{l}\text { Willing to act as soon } \\
\text { as possible }\end{array}$ & $\begin{array}{l}\text { Willing to watch for } \\
\text { any new } \\
\text { developments very } \\
\text { carefully }\end{array}$ & Do not care \\
\hline 8 & Expected first-year revenue & Large & Average & Small \\
\hline $\mathbf{9}$ & Required investment over next 12 months & Above average & Average & Below average \\
\hline
\end{tabular}

Table 2. Classification of the value propositions of the startups with respect to their market offers

\begin{tabular}{|c|c|c|}
\hline Type & Market Offer Description & Number of firms \\
\hline $\mathbf{A}$ & $\begin{array}{l}\text { Access to online printing networks allowing both printing services and offering the use of } \\
\text { privately owned printers at a cost as part of the network resources (i.e., the firms managing the } \\
\text { networks do not own the printers). }\end{array}$ & 14 \\
\hline $\mathbf{B}$ & $\begin{array}{l}\text { Online printing services offered through a platform enabling the access to a network of } 3 \mathrm{D} \\
\text { printers. The firms managing the networks own the printers. }\end{array}$ & 12 \\
\hline C & Design tools and software applications for 3D modelling. & 4 \\
\hline $\mathbf{D}$ & 3D model-generation products such as scanners or special cameras. & 4 \\
\hline $\mathbf{E}$ & Commercial 3D printers that anyone can afford to purchase. & 15 \\
\hline $\mathbf{F}$ & $\begin{array}{l}\text { Online } 3 \mathrm{D} \text { printing services with a focus on a particular application such for printing action } \\
\text { figures or toys. }\end{array}$ & 5 \\
\hline G & Specialized applications of 3D printing (usually business-to-business). & 4 \\
\hline Other & Individual market offers that are different from the ones given above. & 21 \\
\hline
\end{tabular}




\section{The Disruptive Potential of the Value Propositions of 3D Printing Technology Startups}

Finn Hahn, Søren Jensen, and Stoyan Tanev

ing services. The online network platform takes care of everything around the job. Second, it offers an option for people or organizations owning 3D printers to integrate their printers as part of the network resources and make revenue through the printing services by sharing that revenue with the network administrators. The access to such networks can be an affordable entrance point for local "maker movements" or just an opportunity to meet other people sharing the same professional interests. The customer has the option of using print service anonymously. Once printed, the object is shipped by mail and the payment can be handled through the company's website.

Type B: Online printing services through a platform enabling the access to a network of $3 D$ printers

Besides getting the desired object printed, the platform makes it easier for customers to either become designers themselves or to access the innovative designs of others. Some of the companies managing such platforms offer tools for collaborative work around the design of the objects, thereby ensuring a growing library of models for the customers and the possibility to be part of the design process.

Type C: Tools and software applications for $3 D$ modelling used in the $3 D$ printing process

The software tools allow customers to easily create and modify $3 \mathrm{D}$ objects and models. In this way, users with no prior CAD knowledge are able to model 3D objects in a convenient and simple way. These tools can be seen as complementary products to the $3 \mathrm{D}$ printing machines, because they enable home users to create their own input models for their 3D printers.

\section{Type D: 3D model-generation products such as scanners} or special cameras

These companies enable customers to convert their own existing 2D pictures into working $3 \mathrm{D}$ scans. In this way, customers can create content for their own 3D printers or share models on the Internet. Further, this technology converts an existing printer into a 3D "copy machine" because it easily allows people to digitize real-world models. These tools can be also seen as complementary products to the 3D printing machines, because they enable home users to capture their own input models for their 3D printers.

\section{Type E: Commercial 3D printers that anyone can afford} to purchase

The direct value for the customers is to be able to print $3 \mathrm{D}$ models at home. Some of the companies are further engaged in delivering less expensive materials for the printing process. One company (Honeycomb Technologies) enables doctors to print customized exoskeletons to support the healing of fractured bones, as an alternative to plaster or fibreglass casts. Further, these printers can significantly lower the barriers to manufacturing. For a few hundred dollars, customers can assemble a small factory that can make fully customized plastic parts for products or they can use printing networks or services.

\section{Type F: Online 3D printing services with a focus on a particular application such as for printing action figures or toys}

The value for the customers is grounded in the opportunities for customization. The high degree of potential customization makes the offer highly valuable for every single customer.

\section{Type G: Special applications of $3 D$ printing (usually business-to-business)}

Customers benefit from access to state-of-the-art advances in $3 \mathrm{D}$ printing technologies and processes, which enable them to do things they were not able to do before (e.g., mass customization). They are also able to enhance existing processes to work faster or better, for example, through enhanced processes for medical doctors or the use of new resins or other materials.

\section{Comparative Analysis of the Different Types of Value Propositions}

The value propositions associated with the seven market offers A to $G$ (Table 2) correspond to $73 \%$ of the firms. The value propositions of the rest of the (or other) firms were based on unique specialized market offers that did not fall into the seven categories given above and were not included in the analysis. Figure 1 shows that the three highest ranking value propositions in terms of business traction are not the ones focusing on the production of $3 \mathrm{D}$ printers, but are those offering design tools and software applications for 3D modelling (market offer type C), 3D model-generation products such as scanners or special cameras (market offer type D), and online 3D printing services with a focus on a particular application such as action figures or toys (market offer type F).

A report by McKinsey \& Company (2013) suggests a similar conclusion: "The success of 3D printing also depends on improvements in products such as design software, 3D scanners, and supporting software applications and tools. Commercial 3D scanners are an important enabling technology." Companies selling 


\section{The Disruptive Potential of the Value Propositions of 3D Printing Technology Startups}

Finn Hahn, Søren Jensen, and Stoyan Tanev

affordable 3D printers (market offer type E) are fourth in the list in terms of their business traction (Figure 1). At the same time, these companies rank highest in terms of the amount of investments and the number of followers interested in knowing about their future progress (Figures 2 and 3).

The three value propositions that rank highest in terms of number of investors in the corresponding companies are selling commercial 3D printers that anyone can afford to purchase (Figure 2, market offer type E), online 3D printing services with a focus on a particular application such as action figures or toys (market offer type F), and companies developing and offering design tools and software applications for 3D modelling (market offer type C). These findings suggest that investors tend to prefer more tangible products that are in the very core of the technology sector.

The three highest ranking value propositions in terms of number of followers of the corresponding companies are selling commercial $3 \mathrm{D}$ printers that anyone can afford to purchase (market offer type E), online 3D printing services with a focus on a particular application such as action figures or toys (market offer type F), and companies with 3D model-generation products such as scanners or special cameras (market offer type D). The comparison between Figures 2 and 3 suggests that followers are attracted to the companies with the highest degree of external investments.

Table 3 provides a quantitative representation of the comparison of the different value propositions in terms of their degree of disruptiveness. It is based on the criteria described in Table 1.

Figure 4 provides a visual representation of the results from the application of the Disrupt-O-Meter tool. The ranking is based on the data presented in Table 3. The Disrupt-o-Meter analysis shows that the offers associ-

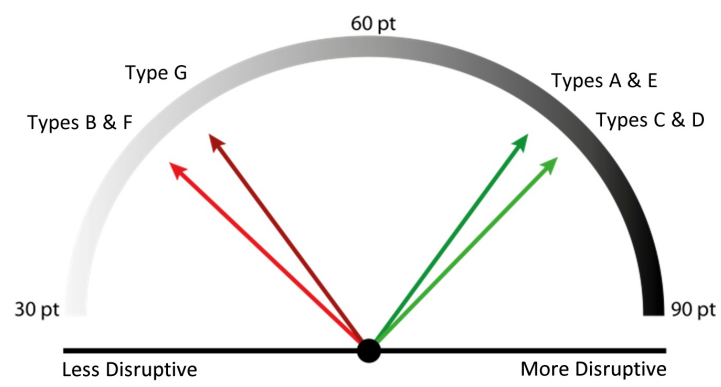

Figure 4. A visual representation of the ranking of the value propositions in terms of degree of disruptiveness

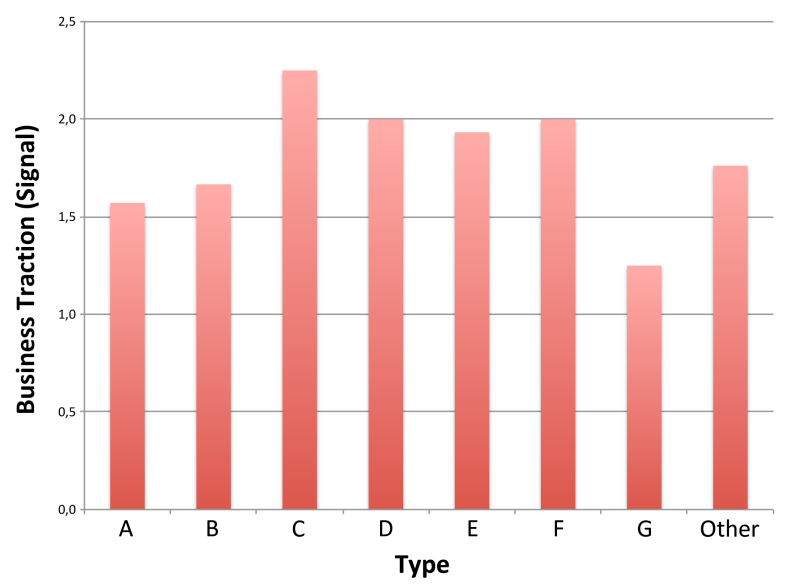

Figure 1. Ranking of the 3D printing value propositions in terms of their business traction

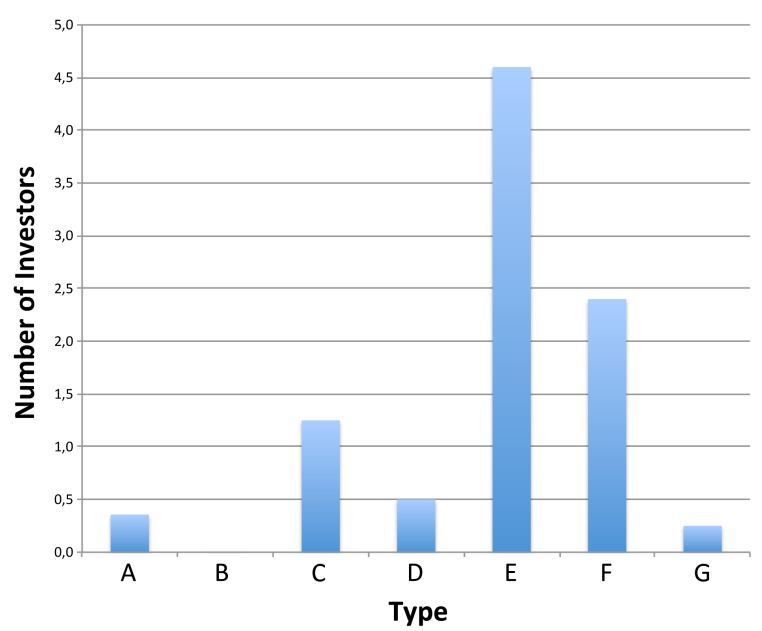

Figure 2. Ranking of the 3D printing value propositions in terms of number of investors

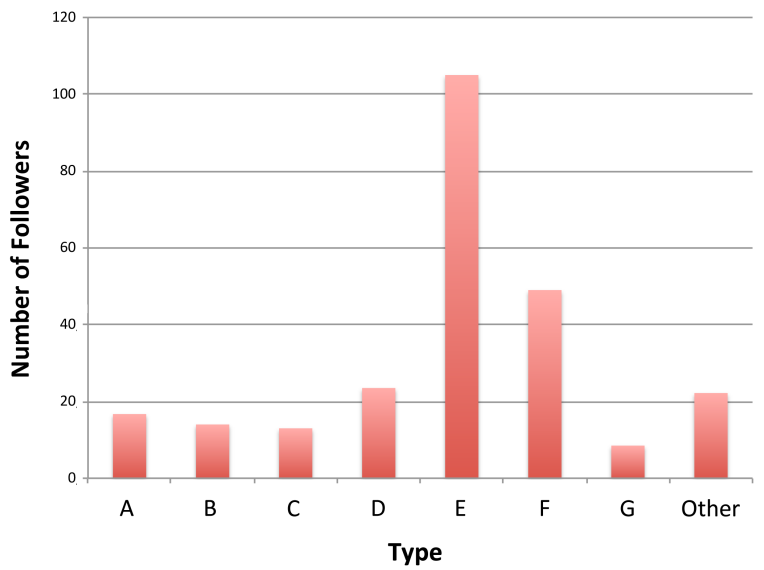

Figure 3. Ranking of the 3D printing value propositions in terms of number of followers 


\section{The Disruptive Potential of the Value Propositions of 3D Printing Technology Startups}

Finn Hahn, Søren Jensen, and Stoyan Tanev

Table 3. Evaluation of the disruptiveness of the different types of market offers on the basis of the Disrupt-O-Meter tool (Anthony et al., 2008)

\begin{tabular}{llccccccc}
\hline & Disruption Criteria & Type A & Type B & Type C & Type D & Type E & Type F & Type G \\
\hline $\mathbf{1}$ & First-year target & 10 & 5 & 10 & 10 & 10 & 10 & 10 \\
\hline $\mathbf{2}$ & Customers' opinion about job to be done & 10 & 10 & 10 & 10 & 10 & $\mathbf{0}$ & 10 \\
\hline $\mathbf{3}$ & Customers' opinion about the offer & 5 & 5 & 10 & 10 & 5 & $\mathbf{0}$ & 5 \\
\hline $\mathbf{4}$ & Customers' opinion about the price & 5 & 0 & 10 & 10 & 10 & $\mathbf{0}$ & 0 \\
\hline $\mathbf{5}$ & Business model & $\mathbf{1 0}$ & 5 & 5 & 5 & 5 & 5 & 5 \\
\hline $\mathbf{6}$ & Channel to market & $\mathbf{1 0}$ & 5 & 5 & 10 & 10 & 5 & 5 \\
\hline $\mathbf{7}$ & Competitors' urgency to act & 5 & 5 & 10 & 5 & 5 & 10 & 5 \\
\hline $\mathbf{8}$ & First-year revenue & $\mathbf{1 0}$ & 5 & 10 & 10 & 10 & $\mathbf{1 0}$ & 5 \\
\hline $\mathbf{9}$ & Investment over next 12 months & $\mathbf{1 0}$ & 5 & 10 & 10 & 10 & $\mathbf{5}$ & 5 \\
\hline & Total points & $\mathbf{7 5}$ & $\mathbf{4 5}$ & $\mathbf{8 0}$ & $\mathbf{8 0}$ & $\mathbf{7 5}$ & $\mathbf{4 5}$ & $\mathbf{5 0}$ \\
\hline
\end{tabular}

ated with model generation (market offer type C) and scanning software applications (market offer type D) are the most disruptive. The next two groups in terms of disruptiveness are the offers associated with online printing networks (market offer type A) and the 3D printers themselves (market offer type E). These results provide an opportunity to compare the disruptiveness of the value propositions to their business traction and the number of external investors.

The comparisons in Figures 5 and 6 show that the ranking of the value propositions in terms of business traction (signal quality) corresponds to the ranking in terms of the degree of disruptiveness but does not correspond to the one based on the number of external investors. This finding has two implications: i) the degree of disruptiveness could be used as a valuable metric in the evaluation of business traction and ii) investors do not seem to consider the degree of disruptiveness when rationalizing their investment decisions.

\section{Conclusion}

This article summarized the results of an empirical study focusing on identifying some of the emerging business opportunities in the 3D printing technology sector. The business opportunities was examined by studying the value propositions of startups operating in

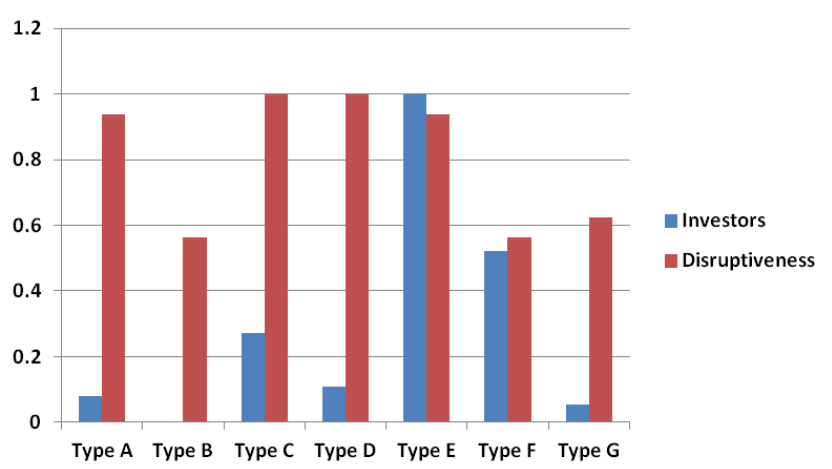

Figure 5. Comparing the disruptiveness of the value propositions to number of investors (normalized units)

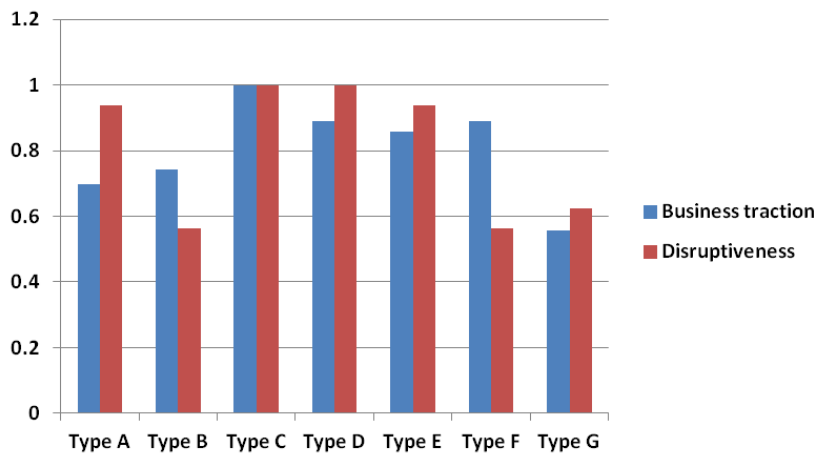

Figure 6. Comparing the disruptiveness of the value propositions to their business traction (normalized units) 


\title{
The Disruptive Potential of the Value Propositions of 3D Printing Technology Startups
}

\author{
Finn Hahn, Søren Jensen, and Stoyan Tanev
}

this technology sector. The assumption is that the value propositions of most recent startups are an indicator of the type of emerging opportunities in a specific sector. The most notable finding is the link between the business traction of 3D printing technology startups and the degree of disruptiveness of their value propositions. Therefore, the main contribution of this study is the empirical support for the conceptualization of the degree of disruptiveness of the value proposition as a metric for the evaluation of the business potential of new technology startups.

The article also contributes to the research stream focusing on 3D printing by discussing emerging business opportunities and suggesting a method for their evaluation. The methodology could be successfully applied to other emerging technologies. The results of the study will be relevant for both academic researchers and stakeholders in the public and private sectors; it may help them evaluate the competitive position of specific value propositions based on 3D printing technologies. It may also be relevant to potential investors who could use the research insights in rationalizing their investment decisions.

\section{Acknowledgements}

An earlier version of this paper was presented at the first ISPIM Americas Innovation Forum in Montreal, Canada, on October 5-8, 2014. The International Society for Professional Innovation Management (ISPIM; ispim.org) is a network of researchers, industrialists, consultants, and public bodies who share an interest in innovation management.

\section{About the Authors}

Finn Hahn is a Product Development Engineer at Egatec A/S in Odense, Denmark. He holds an MSc (Eng) degree in Product Development \& Innovation from the University of Southern Denmark and a BEng in Interaction Design. His special interest is in shaping technology in a way that technology products and systems become more meaningful to people. Finn is also working with entrepreneurship and business-development strategies where he is trying to incorporate the insights gained in the area of interaction design.

Søren Jensen is an Associate Professor in the Faculty of Engineering at the University of Southern Denmark. Previously, he worked in a seed-financing company analyzing technology business ideas. As investment analyst, his special interests lay within intellectual property and technology assessment. He now teaches intellectual property and entrepreneurial business understanding. Søren is also Head of the PDI MSC engineering program, an interdisciplinary engineering program training students to act on the border between technical and business understanding.

Stoyan Tanev is an Associate Professor in the Department of Technology and Innovation at the University of Southern Denmark, Odense, as well as Adjunct Professor in the Department of Systems and Computer Engineering at Carleton University in Ottawa, Canada, where he was previously a faculty member in the Technology Innovation Management Program. He has a MSc and a PhD in Physics jointly from the University Pierre and Marie Curie in Paris, France, and the University of Sofia, Bulgaria. He also holds a PhD in Theology from the University of Sofia, Bulgaria, an MEng in Technology Innovation Management from Carleton University in Ottawa, Canada, and an MA from the University of Sherbrooke, Canada. He has multidisciplinary research interests with a focus on the fields of technology entrepreneurship and innovation management, bornglobal technology startups, business model design, and value co-creation. Dr. Tanev is a Senior IEEE member, and he is a member of the editorial boards of the Technology Innovation Management Review and the International Journal of Actor-Network Theory and Technological Innovation. 


\section{The Disruptive Potential of the Value Propositions of 3D Printing Technology Startups}

Finn Hahn, Søren Jensen, and Stoyan Tanev

\section{References}

Anthony, S., Johnson, M., Sinfield, J., \& Altman, E. 2008. The Innovator's Guide to Growth: Outting Disruptive Innovation at Work. Boston, MA: Harvard Business Press.

Christensen, C. 2006. The Ongoing Process of Building a Theory of Disruption. Journal of Product Innovation Management, 23(1): 39-55.

http://dx.doi.org/10.1111/j.1540-5885.2005.00180.x

Cohendet, P., \& Pénin, J. 2011. Patents to Exclude vs. Include: Rethinking the Management of Intellectual Property Rights in a Knowledge-Based Economy. Technology Innovation Management Review, 1(3): 12-17.

Cozmei, C., \& Caloian, F. 2012. Additive Manufacturing Flickering at the Beginning of Existence. Procedia Economics and Finance, 3: 457-462.

http://dx.doi.org/10.1016/S2212-5671(12)00180-3

Hang, C. C., Chen, J., \& Yu, D. 2011. An Assessment Framework for Disruptive Innovation. Foresight, 13(5): 4-13.

http://dx.doi.org/10.1108/14636681111170185
Johnson, M., Christensen, C., \& Kagermann, H. 2008. Reinventing Your Business Model. Harvard Business Review, 86(12): 50-59.

MacMillen, D., Butts, M., Camposano, R., Hill, D., \& Williams, T. 2000. An Industrial View of Electronic Design Automation. IEEE Transactions on Computer Aided Design of Integrated Circuits and Systems, 19(12): 1428-1448.

http://dx.doi.org/10.1109/43.898825

McKinsey \& Company. 2013. Disruptive Technologies: Advances That Will Transform Life, Business, and the Global Economy. McKinsey Global Institute. Accessed December 1, 2014:

http://www.mckinsey.com/insights/business_technology/disruptiv e_technologies

Royal Academy of Engineering. 2013. Additive Manufacturing: Opportunities and Constraints. London: Royal Academy of Engineering.

Schmidt, G., \& Druehl, C. 2008. When Is a Disruptive Innovation Disruptive? Journal of Product Innovation Management, 25: 347-369. http://dx.doi.org/10.1111/j.1540-5885.2008.00306.x 